\title{
Size reduction ascending aortoplasty: Is it dead or alive?
}

\author{
Francis Robicsek, MD, PhD \\ Joseph W. Cook, MD \\ Mark K. Reames, Sr, MD \\ Eric R. Skipper, MD
}

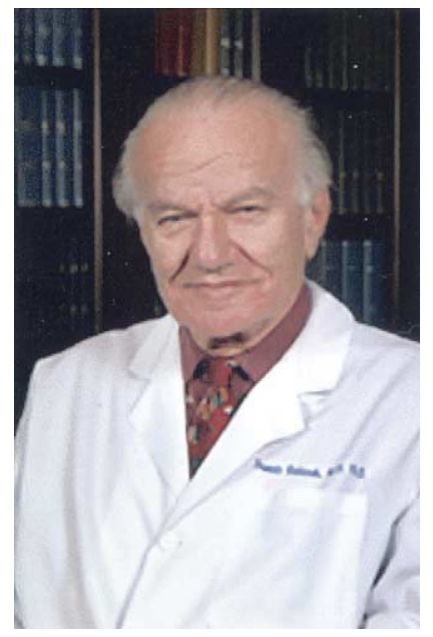

Dr Robicsek

See related editorial on page 499.

\footnotetext{
From the Department of Thoracic and Cardiovascular Surgery and Heineman Medical Research Laboratories at Carolinas Medical Center, Charlotte, NC.

Received for publication Dec 2, 2003; revisions received Feb 17, 2004; accepted for publication April 19, 2004.

Address for reprints: Francis Robicsek, MD, PhD, 1001 Blythe Blvd, Suite 300, Charlotte, NC 28203 (E-mail: frobicsek@sanger-clinic.com).

J Thorac Cardiovasc Surg 2004;128:562-70 $0022-5223 / \$ 30.00$

Copyright () 2004 by The American Association for Thoracic Surgery

doi:10.1016/j.jtcvs.2004.04.032
}

Objective: Reduction ascending aortoplasty is a controversial procedure. Some believe that it can be appropriately applied when the anatomic features are favorable. Others suggest that it should be restricted to those patients who are at unacceptably high risk for more radical procedures, and there are also those who believe that reduction ascending aortoplasty should not be applied at all. The purpose of the article is to draw conclusions on the applicability of reduction ascending aortoplasty in modern cardiovascular surgery.

Methods: The issue was examined in the mirror of the authors' own experiences, by review and scrutiny of the literature available on the subject, and by conducting an extensive survey of the profession.

Results: We found that given proper indications (ie, poststenotic dilatations of $<6$ $\mathrm{cm}$ in diameter, absence of cystic medial necrosis, and a technique that decreases aortic diameter to $<3.5 \mathrm{~cm}$ ), nonreinforced reduction ascending aortoplasty performed concomitantly with aortic valve replacement appears to be a simple and safe procedure, with low morbidity and mortality and rare late complications. External reinforcement might extend the scope of indication for reduction ascending aortoplasty to ascending aortic aneurysms associated with aortic regurgitation and to those with primary structural aortic wall disease with comparable results. Experience also has shown that late complications might be further reduced by means of proper proximal anchoring and extending the wrap past the origin of the innominate artery.

Conclusions: We conclude that reduction ascending aortoplasty is certainly alive. Although it does not appear to be an extremely popular operation, about half of the surgeons who responded believe it to be justified. Regardless of which modality is used, lifetime monitoring of ascending aortic size is essential and so advised. Because of recent sporadic reports of "under-the-wrap" aortic wall atrophy and rupture, the issue of reinforcement of reduction ascending aortoplasty requires continued re-evaluation.

\section{Differences in anatomy may require different techniques.} - Thierry Carrel, $1991^{1}$

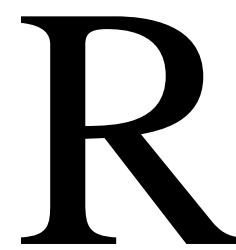
eduction ascending aortoplasty (RAA) is a controversial operation. Some believe that it can be appropriately applied when the anatomic features are favorable. Others suggest that it should be restricted to those patients who are at unacceptably high risk for more radical procedures, and there are also those who believe that RAA should not be applied at all. The purpose of this article is to examine the subject in the mirror of our own experiences, by reviewing related literature, and by conducting an extended survey of the profession and to draw conclusions on the applicability of RAA in modern cardiovascular surgery.

\section{Background}

The integrity of the aortic wall depends on its holding power, as defined by its biologic properties and by the mural stress acting upon it. The latter is proportional with the diameter 


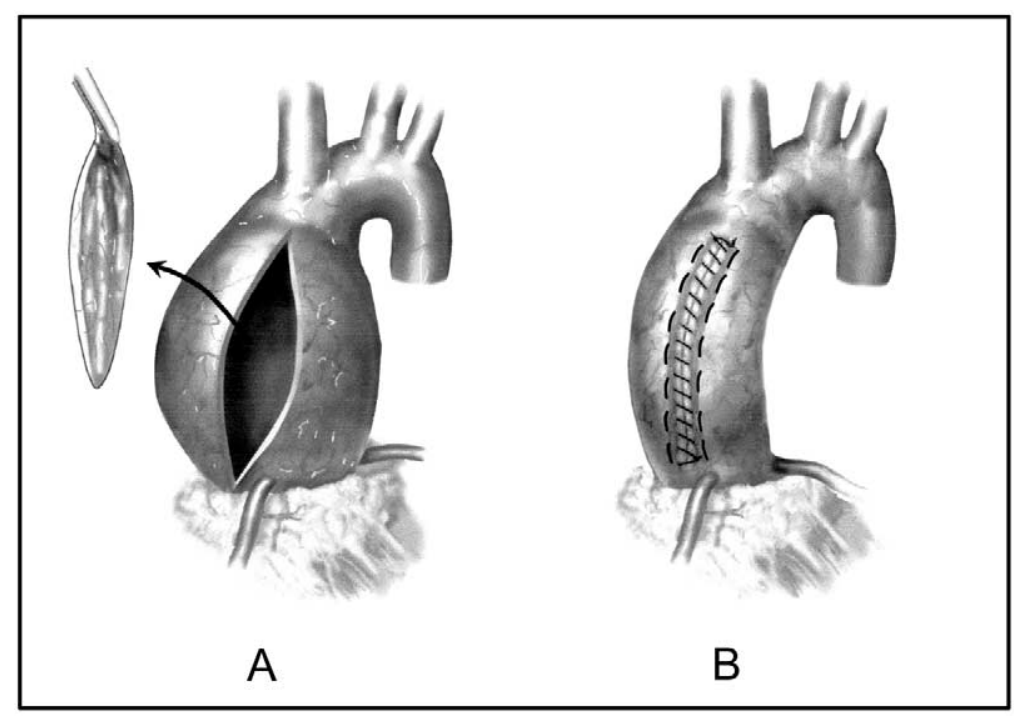

Figure 1. Reduction aortoplasty. An oval segment is excised of the maximal convexity of the ascending aorta, thus reducing its diameter to normal $(A)$, and then the aortotomy is closed with a running mattress and an over-and-over nonabsorbable suture (B).

of the aorta and the blood pressure within and relates inversely to the thickness of its wall. Depending on these factors, ${ }^{2}$ ascending aortic aneurysms (AscAs) are expected to expand gradually, the risk of eventual rupture at a diameter of 5 to $6 \mathrm{~cm}$ is a yearly $6.5 \%$, and the major adverse event rate (rupture, dissection, or death) is expected to be $14 \%$ per year. ${ }^{3}$ The data strongly support a preemptive surgical approach intended to lessen mural stress, either by means of graft replacement or, in selected cases, by means of the more conservative approach of RAA. Such a need to address the dilated ascending aorta is encountered in $5 \%$ to $15 \%$ of all patients undergoing aortic valve surgery. ${ }^{1}$

The differences between AscAs and aortic aneurysms at other locations are significant. AscAs are especially common in patients with aortic stenosis ${ }^{4-6}$; however, they can also occur in those with clinically normal congenitally bicuspid aortic valves. ${ }^{7}$ Although the prevalent view today is that the same inborn defect that causes bicuspid valve anomaly might lead to ascending aortic wall weakness as well, ${ }^{8,9}$ our recent studies indicate that congenitally bicuspid valves, even if asymptomatic and with no appreciable pressure gradient, are morphologically stenotic enough to generate significant turbulence and cause poststenotic aneurysmal dilatation. ${ }^{7}$ Patients with cystic medial necrosis also frequently have AscAs.

Most AscAs are less than $6 \mathrm{~cm}$ in diameter, convex to the right, either fusiform symmetrical or slanted to the right, and easy to isolate. Their lining is smooth and without atheromas, ${ }^{6}$ the wall is thin or of normal thickness, the layers are recognizable, and mural clots are notably absent. Dissections occur frequently, but rupture without dissection is relatively rare.

Contrary to the above, the overwhelming majority of abdominal aortic aneurysms are of atherosclerotic origin and occur in various sizes, shapes, and wall thicknesses. The layers are distorted by atherosclerosis and mural thrombi are common, and because of adherence, side branches, and frequent inflammatory response, they might be difficult to isolate during surgical intervention.
These differences make RAA suitable for the treatment of AscAs but much less likely for the treatment of aortic aneurysms at other locations.

\section{Surgical Technique}

RAA consists of the excision of an oval segment of the anterior or anterolateral ascending aortic wall in the axial direction, with the aim of reducing its caliber to a normal level. The operation is commonly done in combination with aortic valve replacement and might be supplemented with circumferential external reinforcement (wrap) with synthetic materials. Although RAA can be performed by using side clamping of the ascending aorta, ${ }^{10}$ in all but a few cases, appropriate diameter reduction requires an open technique. Other types of ascending aortoplasties include partial replacement, ${ }^{11}$ limited resection with end-to-end anastomosis, ${ }^{12,13}$ plication, ${ }^{14}$ plication-like procedures, ${ }^{15-18}$ or any combination of these. External reinforcement can also be performed without RAA. ${ }^{19-24}$

Femoral or axillary arterial cannulation might make the aortic arch less crowded and the operation simpler. Dissection of the ascending aorta is carried out off pump, with the heart beating, to reduce bypass time. After institution of cardiopulmonary bypass, the aortotomy is performed following the greater curvature of the aorta, which is more often than not toward the right of the midline. The incision should begin just proximal of the crossclamp and extend into the noncoronary sinus. Scoring the aorta with a marking pen before crossclamping will ensure symmetric excision and undistorted closure. When indicated, the aortic valve is replaced first, followed by excision of a semielliptical portion of the aortic wall on both sides of the aortotomy, reducing the aortic diameter to about $3.5 \mathrm{~cm}$ when closed (Figure 1).

When a surgeon decides to reinforce the RAA, an oversized Dacron vascular prosthesis is cut in length, split open longitudi- 


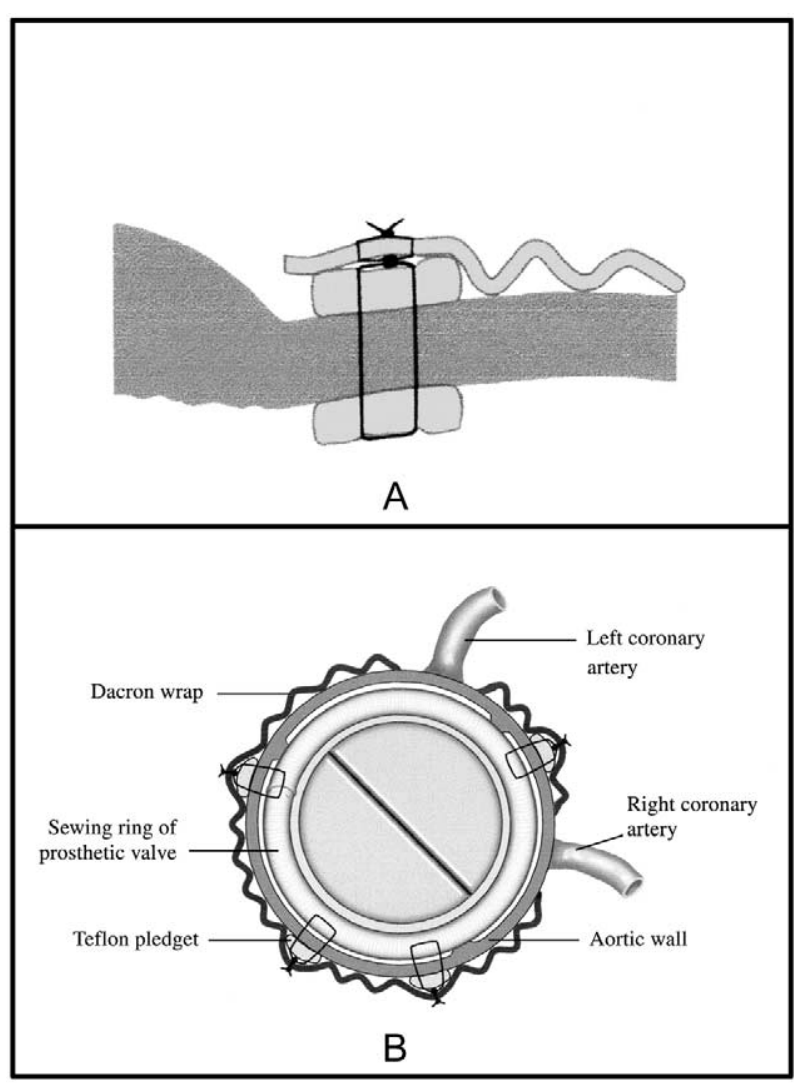

Figure 2. Buttressing the proximal anchoring sutures with Teflon pledgets (A) or, if the aortic valve is also replaced, with the sewing ring of the valve prosthesis (B).

nally, and placed around the ascending aorta to extend beyond but spare the origin of the innominate artery. Using the wrap with its groves in the axial instead of the transverse direction or using a knitted prosthesis ${ }^{25}$ will allow some aortic expansion, and for this reason, it is discouraged. Materials such as polypropylene, nylon, ${ }^{23,26}$ and knitted ${ }^{25}$ and woven Dacron ${ }^{23}$ have been used to reinforce (wrap) the RAA. Of these, we found woven Dacron to be the most suitable. The cardiac end of the wrap is anchored with pledgeted sutures driven through the aortic wall inside out at the right and the posterior commissure slightly anterior to the left commissure and then tied over a second Teflon pledget, passed through the wrap, and tied again (Figure 2, A). When the aortic valve is replaced, these sutures are buttressed internally, not with pledgets but with the sewing ring of the valve prosthesis (Figure 2, $B$ ). After the aortotomy is closed with an over-and-over running suture followed with a continuous mattress stitch, the patient is weaned from cardiopulmonary bypass. The wrap is then tailored to fit snugly but not too constricting. Small semicircles of wrap are excised around the takeoff of the right and left coronary arteries to avoid encroachment on the coronary orifices. The wrap is then closed with a running, nonabsorbable suture (Figure 3, $A$ and $B$ ).

If coronary bypass grafting is also required, the vein grafts might be brought through the wrap through appropriately placed openings (Figure 3,C). It has been suggested ${ }^{27}$ that complete coverage of the involved aortic segment, including the areas proximal to the rise of the coronary arteries, is required to prevent redilatation. In our view dissection and maneuvering of the wrap around the coronary orifices is unnecessary because the area left uncovered, being small and noncircumferential, will not dilate.

The event, which has been identified as "migration of the wrap," is a potential cause of aneurysm formation after reinforced RAA. ${ }^{25,26,28}$ This can occur when areas of the aortic wall adjacent to the wrap's edge that were initially covered by the wrap become exposed again. In our opinion this might happen not necessarily through retraction of the wrap but rather because the aortic wall is pulled out from under it by successive proximal or distal dilatation of the aorta (Figure 4). Proximal anchoring and carrying the reinforcement past the innominate artery will prevent such an event (Figure 5).

Several modifications of the conventional RAA have been recommended. Harrison and Heck, ${ }^{16}$ instead of removing an oval piece of the aortic wall, decreased the aortic caliber by means of open plication with a double suture line (shawl-aortoplasty). Baumgartner and colleagues ${ }^{29}$ suggested that the aortotomy should be $\mathrm{S}$ shaped rather than linear. Cotrufo and colleagues ${ }^{17,18}$ created an arched, double-layer, autologous reinforcement of the right lateral aspect of the aorta (waistcoat aortoplasty, Figure 6). Because wall stress in aneurysms is primarily circumferential, it is dubious whether the risk of additional dilatation and eventual rupture can be lowered by either of these techniques.

\section{Review of the Literature}

In 1956, Bahnson and Nelson ${ }^{10}$ used side clamping in 4 patients with AscA and Marfan disease, excised a portion of the dilated aorta, and enclosed the area of resection with a nylon binder. The aorta in one patient (possibly others) was chronically dissected. One patient was lost during surgical intervention, and 2 died 5 and 6 months later, respectively.

After Bahnson's report, which, like many of his publications, was way ahead of its time, the literature was silent on RAA for 13 years. In 1969 , Jortner and associates ${ }^{30}$ presented a case of a child with Marfan disease and acute dissection treated with "excision of the aneurysm, endo-aneurysmorrhaphy and reinforcement of the ascending aorta with a Dacron cuff." It is unclear as to the nature of the "endo-aneurysmorrhaphy," but it is unlikely that the procedure would qualify as an RAA in current terms. The situation was similar in the Mayo Clinic's series reported by McCready and Pluth in $1969,{ }^{31}$ in which 111 patients underwent aortic valve replacement for regurgitation combined with repair of AscA. Fiftyfour percent of the patients had cystic medial necrosis, and $21 \%$ had chronic dissection. Thirty-one of these had various forms of nonreinforced "aortoplasties," including patch repairs. The latter group had a higher perioperative morbidity and mortality compared with those treated with ascending aortic replacement. In the "aortoplasty" group, there was also one late death caused by rupture, and one intervention for redilatation.

Between 1969 and 1979, of 860 operations for a variety of aortic aneurysms, we applied external reinforcement in 84 patients, with a hospital mortality of $8 \%$. During an observation period extending up to 12 years, we encountered only a single case of aortic rupture..$^{24,32-34}$ Others ${ }^{19,23,35,36}$ had similar favorable experiences; however, Dhillon and coworkers ${ }^{37}$ and Smith and associ- 


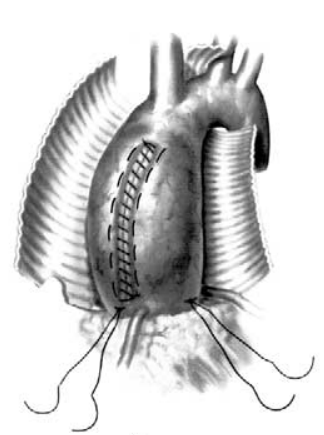

A

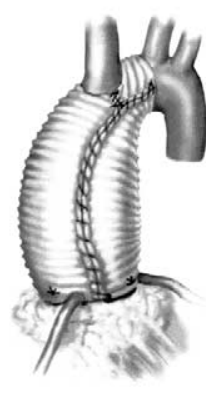

B

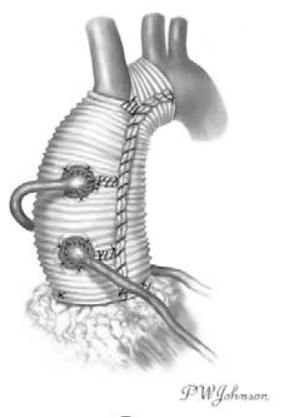

C

Figure 3. Externally reinforced reduction aortoplasty. A cut-open Dacron vascular prosthesis is placed around the ascending aorta, which is already decreased in diameter. Note the presence of the proximal anchoring sutures (A). The Dacron wrap is tailored snug but not constricting, carried past the origin of the innominate artery, and closed with a running, nonabsorbable suture (B). Coronary bypass grafts can be brought through holes made in the wrap (C).

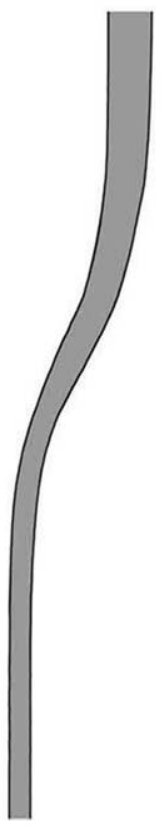

A

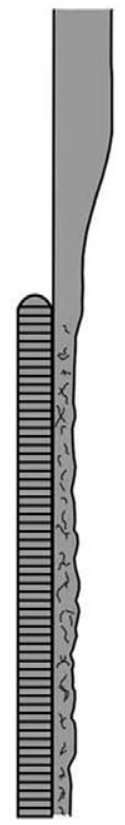

B

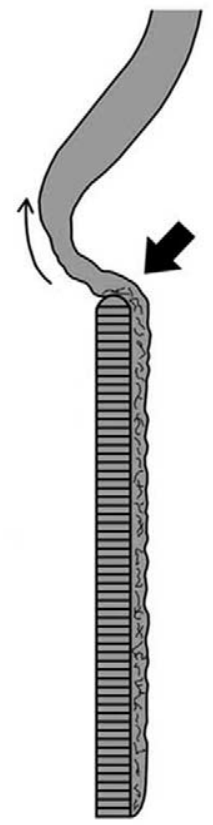

C

Figure 4. Mechanisms of how aortic rupture might occur despite external reinforcement. The aortic wall, which might already be thin because of the dilatation (A), can undergo additional under-the-wrap atrophy (B). Subsequent dilatation of the aorta distal to the uncovered segment might pull the aorta out from under the wrap and create a buckle and a spot of weakened resistance (arrow, C). Rupture under the wrap can be caused by atrophy alone (D).

ates $^{20}$ reported several patients treated similarly who had late complications, including rupture. Giving consideration to these reports, we began to combine external reinforcement with RAA by using the open technique and cardiopulmonary bypass. During the years of 1979 through 1994, we performed RAA in 28 patients with fusiform AscAs of moderate size $(<5.5 \mathrm{~cm})$. Four of these patients with Marfan disease had RAA only, and 24 had aortic valve replacement as well. Two patients in the latter group died in the hospital from causes unrelated to RAA. ${ }^{38}$ Only approximately two thirds of the patients were followed past 5 years. Of these, 


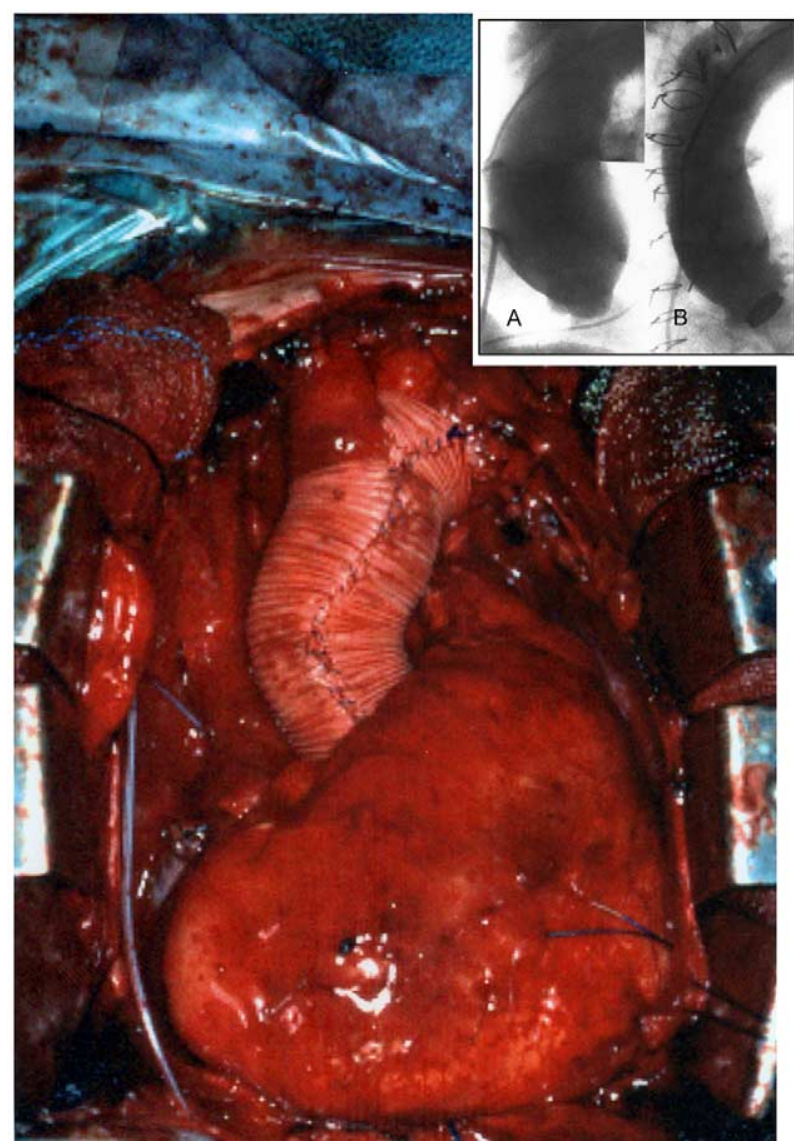

Figure 5. Completed externally reinforced ascending aortoplasty. Preoperative (A) and postoperative (B) angiograms are shown in the upper corner. (From Robicsek F. About ascending aortic dilatation during aortic valve replacement. J Cardiovasc Surg [Torino]. 2003;44:279; reproduced with permission.)

there were 4 known late deaths, 2 of them definitely not attributable to aortic rupture, and 2 of unknown cause. ${ }^{38}$

During the following 2 decades, there were several additional reports on RAAs. Some of the authors performed RAA only, $5,17,18,29,31,39,40$ and others applied external reinforcement as well, either selectively ${ }^{26,41}$ or in all of their patients. ${ }^{25,27}$ The principal clinical data of these publications are condensed in Table $1^{1,5,6,17,25-27,29,40-42}$

\section{Survey}

Questionnaires were sent to 5800 members of the Society of Thoracic Surgeons and European Association for Cardio-thoracic Surgery. We have received 867 (14.95\%) responses. Of these, 646 $(75.1 \%)$ were from the United States, and $221(25.5 \%)$ were from other countries. Five hundred eighty-nine $(67.9 \%)$ of the $867 \mathrm{did}$ and $278(32.1 \%)$ did not perform RAAs.

The 589 respondents performed 4436 RAAs altogether, and of these, $2820(63.6 \%)$ were done concomitantly with operations for aortic stenosis, 1308 (29.4\%) for aortic regurgitation, and 308 $(6.9 \%)$ as an independent procedure.
Information as to whether the RAA was reinforced was given in $3312(74.7 \%)$ cases; $1387(41.7 \%)$ of these were reinforced, and $1925(58.1 \%)$ were not. The late complications occurring in the 3312 patients are shown in Table 2 .

Of 772 respondents, $414(53.6 \%)$ believed that given specific morphology, RAA is an appropriate procedure, whereas 343 (44.4\%) thought that it should not be applied at all. Fifteen $(1.94 \%)$ had no opinion on the subject. Seven hundred sixty responded to the question of whether the surgical mortality of RAA is expected to be lower than that of more radical operations. Three hundred sixty-two (47.6\%) thought it was lower, $378(49.7 \%)$ thought that that it was not, and $20(2.6 \%)$ had no opinion. Of 809 surgeons responding on the subject of preoperatively known or suspected Marfan disease, $594(73.4 \%)$ regarded it as a contraindication of RAA, $144(17.8 \%)$ did not believe it to be a contraindication, and $71(8.8 \%)$ had no opinion.

\section{Discussion}

In times when serious efforts are made to preserve the native aortic valve, it appears illogical to discard the native ascending aorta. It is intuitively obvious that it is desirable to leave the endotheliumlined aorta where it is, reinforce it from the outside with a graft inside the aorta, and then close the aorta around it. ${ }^{43}$ However, in surgical intervention it is not always the most logical method that necessarily provides the best results.

In the debate of RAA versus ascending aortic replacement, issues of indication, the risks of the operation, and late complications seem to be most important.

The indication for RAA is greatly influenced by morphology. Of the 3 principal forms of AscA-ie, poststenotic, annuloectatic (marfanoid), and tubular - the poststenotic form, which represents about $13 \%$ of all AscAs, appears most suitable for RAA, especially if the patient who undergoes aortic valve replacement is elderly or is at high risk for any other reason. In both the quoted literature and in the survey, we found a general agreement that patients with AscAs with a diameter of greater than $6 \mathrm{~cm}$ and those that are saccular rather than fusiform, have significant dilatation of either the annulus or sinuses, or both, should not undergo RAA. ${ }^{17,18,41} \mathrm{~A}$ specific reason recommended for aortoplasty is that of Svensson and colleagues, ${ }^{44}$ who applied it to patients likely to return for additional procedures, such as coronary bypass grafting.

We were somewhat surprised that approximately half of the surgeons in the survey expressed the view that the operative risks of RAA are similar to those of more radical procedures, such as the Bentall operation. This might be either an understatement or a reflection of some superb clinical performances that could be difficult to duplicate. ${ }^{45}$ Statistics of institutions with considerable experience indicate that graft replacement of the ascending aorta still remains a technical challenge entailing significant risk, with perioperative mortality varying from $1.5 \%$ up to $10 \%$. $^{3,44-50}$

Immer and coworkers ${ }^{49}$ studied 73 patients who met the criteria for RAA but underwent ascending aortic graft replacement instead. The hospital's mortality was $9.6 \%$, the late mortality was $4 \%$, and neurologic complications occurred in $6.7 \%$ of the patients. Elefteriades ${ }^{3}$ found the risk of surgical mortality for AscA surgery to be $2.5 \%$ and the chance of perioperative stroke to be $8 \%$, even in the hands of the "most experienced operators." In contrast, with a 


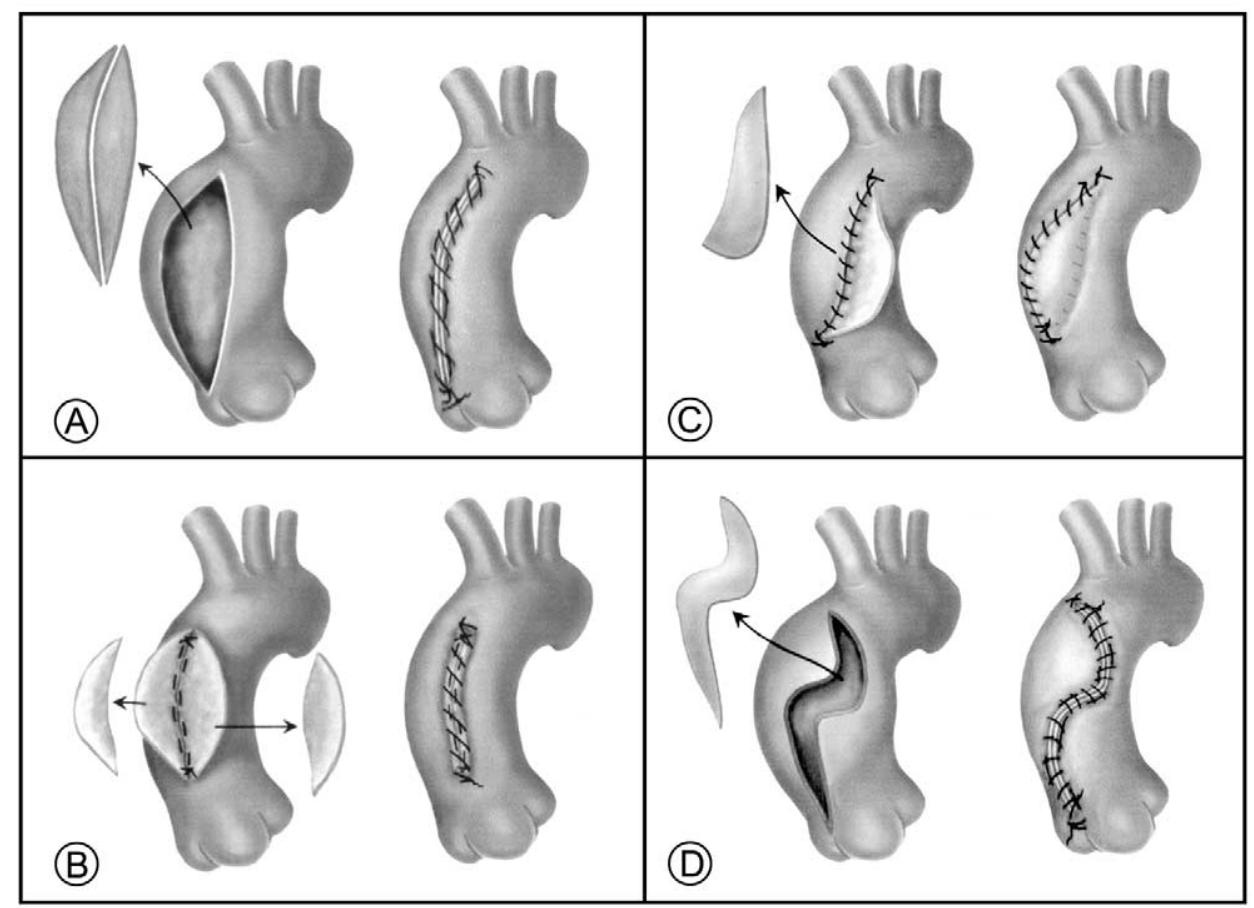

Figure 6. Different aortoplasty closures: Robicsek (A),$^{51}$ Harrison and Heck $(B),{ }^{16}$ Cotrufo and colleagues $(C),{ }^{18}$ and Baumgartner and associates (D). ${ }^{29}$

single known exception, ${ }^{40}$ no procedure-related severe morbidity or mortality attributable to RAA per se has ever been reported.

To be fair, however, it needs to be emphasized that none of the series comparing results of RAAs with those of more radical procedures were ever randomized, and bias in selection is not only likely but probable. The indication for RAA was limited to aneurysms of moderate sizes, ${ }^{1,29,39,41}$ and in several series patients with Marfan disease, dissection, or both were also excluded. ${ }^{17,18,25,27,29,41}$ Some authors, however, chose RAA for a particular patient because of the higher surgical risk of more complex procedures. ${ }^{6,38}$

Because of a lack of procedural mortality and low morbidity in comparing the merits and disadvantages of the two procedures, long-term results are especially important. Estimation of these, however, is difficult because of the various criteria applied by different surgeons in both indication and technique. Thus it is entirely possible that the occurrence of some late complications (ie, redilatation and rupture) are not inherent to RAA but were consequences of selection and technique. Because the majority of our colleagues see it because patients with Marfan disease tend to redilate in the absence of external support, the presence of any genetic disorder of the aortic wall should contraindicate use of unsupported RAA.

For all practical reasons, the above considerations leave only AscAs induced by aortic stenosis (poststenotic type) suitable for unsupported RAAs. ${ }^{1,5}$ In patients with aortic regurgitation, more often than not the sinuses are enlarged, the dilatation of the ascending aorta is tubular, the dilatation might extend beyond the origin of the innominate artery, and the aortic wall tends to be thinner and more friable. For these reasons, aortic regurgitation appears to be a risk factor per se for redilatation after unsupported RAA. ${ }^{5}$ On the other hand, implantation of a prosthetic aortic valve favorably influences the outcome of RAA by stabilizing the aortic orifice and facilitating proximal anchoring.

The applicability of reinforced RAA is broader because, given proper technique, redilatation of the ascending aorta is less likely to occur, even in patients with cystic medial necrosis. For this reason, in the past, we $\mathrm{e}^{38,51}$ and others ${ }^{1,25,27}$ have advocated that all RAAs should be externally reinforced. In young individuals with known Marfan disease and mild $(3.5-4 \mathrm{~cm})$ ascending aortic dilatation, it would seem reasonable to treat these aortas with reinforced RAA because of the hazard of dissection. ${ }^{38}$ Such an early approach would also prevent the development of aortic regurgitation, which is usually caused by dilatation of the ascending aorta. ${ }^{52}$ The application of reinforced RAA in such patients, however, now needs to be reconsidered in view of sporadic reports indicating that occasional rupture after RAA might occur despite external reinforcement. ${ }^{28,53}$

The article by Neri and colleagues, ${ }^{53}$ published in 1990 , describes two patients who, after having undergone aortic valve replacement and reinforced RAA 7 and 11 years previously, required reoperation because of development of false aneurysms. The unwrapped parts of the ascending aorta in both patients appeared normal; conversely, the aortic wall underlying the wrap was severely atrophic, a phenomenon previously reported with abdominal aneurysms that were wrapped without aortoplasty. ${ }^{20,37}$ In both cases rupture occurred on the posterior aspect of the wrapped aorta distant to the aortotomy suture line. Atrophy under the wrap has also been reported by Bauer and coworkers ${ }^{28}$ in a 53-year-old patient who underwent aortic valve replacement and 
TABLE 1. Literary review

\begin{tabular}{|c|c|c|c|c|c|c|c|}
\hline \multirow[b]{2}{*}{ Author } & \multicolumn{2}{|c|}{ No. of patients } & \multicolumn{2}{|c|}{ Aortoplasty } & \multirow[b]{2}{*}{ Follow-up } & \multirow[b]{2}{*}{$\begin{array}{l}\text { No. of } \\
\text { redilatations }\end{array}$} & \multirow[b]{2}{*}{ Notes } \\
\hline & $\begin{array}{c}\text { Not } \\
\text { reinforced }\end{array}$ & Reinforced & $\begin{array}{l}\text { RAA } \\
\text { only }\end{array}$ & $\begin{array}{l}\text { With aortic } \\
\text { valve } \\
\text { surgery }\end{array}$ & & & \\
\hline $\begin{array}{l}\text { Egloff and coworkers } \\
\qquad(1982)^{26}\end{array}$ & 21 & 17 & - & 29 & $45 \mathrm{mo}$ & 8 & $\begin{array}{l}\text { All } 3 \text { redilatations in the } \\
\text { reinforced group were } \\
\text { caused by } \\
\text { "displacement of } \\
\text { Nylon-net," } 2 \text { had } \\
\text { Marfan syndrome. Five } \\
\text { nonreinforced cases } \\
\text { were redilated. There } \\
\text { were } 4 \text { late deaths } \\
\text { (caused by rupture?) }\end{array}$ \\
\hline $\begin{array}{l}\text { Mueller and coworkers } \\
(1997)^{5}\end{array}$ & 15 & - & - & 15 & $6 \mathrm{y}$ & 4 & $\begin{array}{l}\text { All redilatations were in } \\
\text { patients with Marfan } \\
\text { syndrome and who } \\
\text { underwent operations } \\
\text { for aortic regurgitation. }\end{array}$ \\
\hline $\begin{array}{l}\text { Carrel and coworkers } \\
(1991)^{1}\end{array}$ & 164 & - & - & 164 & $6 y$ & 6 & \\
\hline $\begin{array}{l}\text { Barnett and coworkers } \\
(1995)^{6}\end{array}$ & 9 & 8 & 1 & 17 & $4.4 \mathrm{y}$ & - & $\begin{array}{l}\text { There were } 3 \text { early and } 2 \\
\text { late deaths, none of } \\
\text { which were related to } \\
\text { aortoplasty. }\end{array}$ \\
\hline $\begin{array}{l}\text { Ogus and coworkers } \\
(2002)^{25}\end{array}$ & - & 22 & - & 22 & $4 \mathrm{y}$ & - & \\
\hline $\begin{array}{l}\text { Baumgartner and } \\
\text { coworkers }(1998)^{29}\end{array}$ & 23 & - & - & 21 & $\begin{array}{c}1.3 \pm 0.8 \\
y\end{array}$ & - & $\begin{array}{l}\text { There was } 1 \text { coronary } \\
\text { bypass and } 1 \text { subaortic } \\
\text { stenosis. }\end{array}$ \\
\hline $\begin{array}{l}\text { Bauer and coworkers } \\
(2002)^{41}\end{array}$ & 106 & 9 & 7 & 109 & $2 y$ & 9 & $\begin{array}{l}\text { All redilatations were } \\
\text { nonreinforced, and the } \\
\text { postreduction diameter } \\
\text { was }<36.6 \pm 3.4 \mathrm{~mm}\end{array}$ \\
\hline $\begin{array}{l}\text { Cotrufo and coworkers } \\
\qquad(2001)^{17,18}\end{array}$ & 73 & - & - & 73 & $2 y$ & - & \\
\hline Oelert $(2003)^{42}$ & - & 43 & - & 22 & $10 y$ & - & \\
\hline $\begin{array}{l}\text { Tsilimingas and Reiter } \\
(2003)^{27}\end{array}$ & - & 26 & - & 26 & $28 \mathrm{mo}$ & - & \\
\hline $\begin{array}{l}\text { Kamada and coworkers } \\
(2003)^{40}\end{array}$ & 10 & - & - & 10 & $3 y$ & 1 & \\
\hline
\end{tabular}

$R A A$, Reduction ascending aortoplasty.

\section{TABLE 2. Complications noted}

\begin{tabular}{lr}
\hline Redilatation only & \\
Nonreinforced & $136(7.1 \%)$ \\
Reinforced & $62(4.5 \%)$ \\
Rupture & \\
Nonreinforced & $67(3.9 \%)$ \\
Reinforced & $21(1.5 \%)$ \\
\hline
\end{tabular}

reinforced RAA 3 years previously and underwent reoperation because of perivalvular leak and left main coronary artery disease. They found "that the Dacron wrapping had moved to the distal part of the ascending aorta, creating a sharp fold at the inner curve." Although the aorta did not rupture, there was rarefaction of the aortic wall in the region of the fold to a degree that tissue of the Dacron material was clearly visible through the remnants of the aortic wall. The participants in our survey also reported a relatively small number (approximately 1.1\%) of late ruptures with reinforced aortoplasty. It is not clear whether these ruptures were inevitable or were caused by less-than-appropriate technique.

\section{Conclusions and Summary}

The value of conclusions drawn from our data are limited by the lack of prospective design. Also, although in some of the studies 
the clinical material presented was concurrent, it was certainly not randomized. Bias was not only present but also bidirectional; in some series only patients with the highest surgical risk were selected, whereas others also included those with the lowest risk factors.

The material presented, however, still allows the following statements to be made:

1. RAA is certainly alive. Although it does not appear to be an extremely popular operation, about half of the surgeons who responded believe it to be justified.

2. Given proper indications (ie, poststenotic dilatations of $<6$ $\mathrm{cm}$ in diameter, absence of cystic medial necrosis, and a technique that decreases aortic diameter to $<3.5 \mathrm{~cm}$ ), nonreinforced RAA performed concomitantly with aortic valve replacement appears to be a simple and safe procedure, with low morbidity and mortality and rare late complications.

3. External reinforcement might extend the scope of indication for RAA to AscAs associated with aortic regurgitation and to those with primary structural aortic wall disease with comparable results. Experience also has shown that late complications might be further reduced by proper proximal anchoring and extending the wrap past the origin of the innominate artery.

4. Regardless of which modality is used, lifetime monitoring of ascending aortic size is essential and so advised.

5. Because of recent sporadic reports of "under-the-wrap" aortic wall atrophy and rupture, the issue of reinforcement of RAA needs continued re-evaluation.

\section{References}

1. Carrel T, von Segesser L, Jenni R, et al. Dealing with dilated ascending aorta during aortic valve replacement: advantages of conservative surgical approach. Eur J Cardiothorac Surg. 1991;5:137-43.

2. Robicsek F, Thubrikar MJ. The mechanism and prevention of aortic dissection in Marfan syndrome. In: Hetzer R, Gehle P, Ennker J, editors. Cardiovascular aspects of Marfan syndrome. Darmstadt, Germany: Steinkopff Verlag GmbH \& Co KG; 1995.

3. Elefteriades J. Natural history of thoracic aortic aneurysms: indications for surgery and surgical versus nonsurgical risks. Ann Thorac Surg. 2002;74(suppl):S1877-98.

4. Robicsek F. "Very long" aortic grafts. Eur J Cardiothorac Surg. 1992;6:536-41.

5. Mueller X, Tevaearai H, Genton C, et al. Drawback of aortoplasty for aneurysm of the ascending aorta associated with aortic valve disease. Ann Thorac Surg. 1997;63:762-7.

6. Barnett M, Fiore A, Vaca K, Milligan T, Barner H. Tailoring aortoplasty for repair of fusiform ascending aortic aneurysms. Ann Thorac Surg. 1995;59:497-501.

7. Robicsek F, Thubrikar MJ, Cook JW, Fowler B. The congenitally bicuspid aortic valve. How does it function? Why does it fail. Ann Thorac Surg. 2004;77:177-85.

8. Natsuaki M, Itoh T, Rikitake K, Okazaki Y, Naitoh K. Aortic complications after aortic valve replacement in patients with dilated ascending aorta and aortic regurgitation. J Heart Valve Dis. 1998;7: 504-9.

9. Fedak P, Mauro P, Verma S, et al. Vascular matrix remodeling in patients with bicuspid aortic valve malformations: implications for aortic dilatation. J Thorac Cardiovasc Surg. 2003;126:797-805.

10. Bahnson HT, Nelson AR. Cystic medial necrosis as a cause of localized aortic aneurysms amenable to surgical treatment. Ann Surg. 1956;144:519-29.

11. Westaby S, Katsumata T, Vaccari G. Coronary reimplantation in aortic root replacement: a method to avoid tension. Ann Thorac Surg. 1999; 67:1176-7.
12. Sternik L, Zehr KJ, Schaff HV. A method of repair for asymmetric aneurysmal dilatation of the ascending aorta. Ann Thorac Surg. 2002; 73:1332-4

13. Vigano M, Rinaldi M, D'Armini AM, et al. Ascending aortic aneurysms treated by cuneiform resection and end-to-end anastomosis through a ministernotomy. Ann Thorac Surg. 2002;74(suppl):S178992.

14. Albes J, Wahlers T. Valve-sparing root reduction plasty in aortic aneurysm: the "Jena" technique. Ann Thorac Surg. 2003;75:1031-3.

15. Frater R. Aortic insufficiency due to aortic dilatation correction by sinus rim adjustment. Circulation. 1986;74(suppl I):I136.

16. Harrison LJ, Heck HJ. Shawl lapel aortoplasty. Ann Thorac Surg. 1996;62:1867.

17. Cotrufo M, De Santo L, Esposito S, et al. Asymmetric medial degeneration of the intrapericardial aorta in aortic valve disease. Int J Cardiol. 2001;81:37-41.

18. Cotrufo M, Della Corte A, De Santo L, De Feo M, Covino F, Dialetto G. Asymmetric medial degeneration of the ascending aorta in aortic valve disease: a pilot study of surgical management. J Heart Valve Dis. 2003;12:127-35.

19. Buxton B, Harlan B. Surgical treatment of fusiform thoracic aortic aneurysms by external reinforcement. Bull Texas Heart Inst Cardiovasc Dis. 1976;3:35.

20. Smith RI, Constantino M, Perdue GJ. Is there a place for external grafting of arterial aneurysms in selected patients? J Cardiovasc Surg (Torino). 1979;20:13-20.

21. McAllister FF. Discussion. Robicsek F, Daugherty HK, Mullen DC, Harbold NB Jr, Masters TN. Is there a place for wall reinforcement in modern aortic surgery? Arch Surg. 1972;105:827-9.

22. Long E. Discussion. Robicsek F, Daugherty HK, Mullen DC, Harbold $\mathrm{NB} \mathrm{Jr}$, Masters TN. Is there a place for wall reinforcement in modern aortic surgery? Arch Surg. 1972;105:824-9.

23. Milgalter E, Laks H. Dacron mesh wrapping to support the aneurysmally dilated or friable ascending aorta. Ann Thorac Surg. 1991;52: 874-6.

24. Robicsek F, Daugherty K, Mullen DC, Harbold NB Jr, Masters TN. Is there a place for wall reinforcement in modern aortic surgery? Arch Surg. 1972;105:827-9.

25. Ogus N, Cicek S, Isik O. Selective management of high risk patients with an ascending aortic dilatation during aortic valve replacement. J Cardiovasc Surg (Torino). 2002;43:609-15.

26. Egloff L, Rothlin M, Kugelmeier J, Senning A, Turina M. The ascending aortic aneurysm: replacement or repair? Ann Thorac Surg. $1982 ; 34: 117-24$

27. Tsilimingas N, Reiter B. Repair of ascending aorta using a new modification of wrapping. The "external circuit." Ann Thorac Surg. 2004. In press.

28. Bauer M, Grauhan O, Hetzer R. Dislocated wrap after previous reduction aortoplasty causes erosion of the ascending aorta. Ann Thorac Surg. 2003;75:583-4.

29. Baumgartner F, Omari B, Pak S, Ginzton L, Shapiro S, Milliken J. Reduction aortoplasty for moderately sized ascending aortic aneurysms. J Card Surg. 1998;13:129-32.

30. Jortner R, Shahin W, Eshkol D, Gueron M, Levy M. Cardiovascular manifestations and surgery for Marfan's syndrome. Dis Chest. 1969; 56(1):24-30.

31. McCready R, Pluth J. Surgical treatment of ascending aortic aneurysms associated with aortic valve insufficiency. Ann Thorac Surg. 1979;28:307-16.

32. Robicsek F, Daugherty HK, Mullen DC. External grafting of aortic aneurysms. J Thorac Cardiovasc Surg. 1971;61:131-4.

33. Robicsek F, Perkins RS, Mullen DC, Daugherty HK, Harbold NB Jr. Fusiform aneurysm of the entire aortic arch. A new surgical approach. J Thorac Cardiovasc Surg. 1972;63:756-9.

34. Robicsek F, Daugherty HK, Mullen DC, et al. Long-range observations with external aortic grafts. J Cardiovasc Surg (Torino). 1976;17: 195-201.

35. Tanabe T, Kubo Y, Hashimoto M, Takahashi T, Yasuda K, Surgie S. Wall reinforcement with highly porous Dacron mesh in aortic surgery. Ann Surg. 1980;191:452-5.

36. Ando M, Okita Y, Morota T, Takamoto S. Thoracic aortic aneurysm 
associated with congenital bicuspid aortic valve. Cardiovasc Surg. 1998;6:629-34.

37. Dhillon J, Randhawa G, Straehley C, McNamara J. Late rupture after Dacron wrapping of aortic aneurysms. Circulation. 1986;74(suppl): I11-4.

38. Robicsek F, Thubrikar MJ. Conservative operation in the management of annular dilatation and ascending aortic aneurysm. Ann Thorac Surg. 1994;57:1672-4.

39. Baumgartner F, Pak S, Ginzton L, Milliken J. Reduction aortoplasty for moderate-sized ascending aortic aneurysms. Ann Thorac Surg. 1995;59:268.

40. Kamada T, Imanaka K, Ohuchi H, et al. Mid-term results of aortoplasty for dilated ascending aorta associated with aortic valve disease. Ann Thorac Cardiovasc Surg. 2003;9:253-6.

41. Bauer M, Pasic M, Schaffarzyk R, et al. Reduction aortoplasty for dilatation of the ascending aorta in patients with bicuspid aortic valve. Ann Thorac Surg. 2002;73(3):720-4.

42. Oelert H. Aortoplasty and wrapping for aneurysms of the ascending aorta. Presented at the Italian Conference of Cardiovascular Disease; April 10-15, 2003; Erice, Italy.

43. Kouchoukos N. Aortic graft-valve (composite) replacement at 20 years: wrap or no wrap? Shunt or no shunt? Ann Thorac Surg. 1989;48:615-6.

44. Svensson LG, Crawford ES, Hess KR, Coselli JS, Safi HJ. Composite valve graft replacement of the proximal aorta: comparison of techniques in 348 patients. Ann Thorac Surg. 1992;54:427-438.
45. Gott VL. Invited commentary. Robicsek F, Thubrikar MJ. Conservative operation in the management of annular dilatation and ascending aortic aneurysm. Ann Thorac Surg. 1994;57:1674.

46. Hilgenberg AD, Akins CW, Logan DL, et al. Composite aortic root replacement with direct coronary artery implantation. Ann Thorac Surg. 1996;62:1090-5.

47. David T. Invited commentary. J Heart Valve Dis. 2003;12(2):12735 .

48. Jault F, Nataf P, Rama A, et al. Chronic disease of the ascending aorta. Surgical treatment and long-term results. J Thorac Cardiovasc Surg. 1994;108:747-54.

49. Immer FF, Barmettler H, Berdat PA, et al. Effects of deep hypothermic circulatory arrest on outcome after resection of ascending aortic aneurysm. Ann Thorac Surg. 2002;74:422-5.

50. Kon ND, Riley RD, Adair SM, Kitzman DW, Cordell AR. Eight-year results of aortic root replacement with the freestyle stentless porcine aortic root bioprosthesis. Ann Thorac Surg. 2002;73:1817-1821.

51. Robicsek F. A new method to treat fusiform aneurysms of the ascending aorta associated with aortic valve disease: an alternative to radical resection. Ann Thorac Surg. 1982;34:92-4.

52. Griepp R. Ascending aorta. Presented at the Aortic Surgery Symposium VIII; May 2-3, 2002; New York.

53. Neri E, Massetti M, Tanganelli $\mathrm{P}$, et al. Is it only a mechanical matter? Histologic modifications of the aorta underlying external banding. J Thorac Cardiovasc Surg. 1999;118:1116-8. 